\title{
EARLY WARNING TERHADAP INSIDEN KEBAKARAN PADA OVER LAND BELT CONVEYOR PABRIK SEMEN MENGGUNAKAN LINEAR HEAT DETECTION SYSTEM
}

\author{
Ratna Ikawati $^{1}$, Widy Wibisono ${ }^{2}$, Mulia F. Nasution ${ }^{3}$, dan Ade Y. Prasetya ${ }^{4}$ \\ ${ }^{1,4}$ ) Magister Manajemen dan ${ }^{2,3}$ ) Magister Manajemen (MK3L) \\ Sekolah Pasca Sarjana Universitas Sahid \\ E-mail: ${ }^{1}$ ratna.ika85@gmail.com, ${ }^{2}$ widy.wibisono@gmail.com , \\ ${ }^{33}$ zaifadly muff@yahoo.co.id,${ }^{4}$ adeyogaprasetya@yahoo.com
}

\begin{abstract}
The cement market is increasingly competitive with the rise of imported cement, which of course must be answered by cement producers among competition. One of the main processes that should not be disturbed is the supply of limestone from quarry to the factory. The safety of people, processes and equipment are certainly necessity for the production process to run smoothly. The problem that can occur in limestone supply is a breakdown on the Overland Belt Conveyor (OLBC) which is caused by a broken roller and causes the belt to tear and potentially fire. For this reason, prevention efforts need to be done with an early warning mechanism to provide alerts to interested parties. Early warning system can be applied to the process because it can detect the beginning of heat so that fires can be prevented. Therefore, it is necessary to install a sensor using optical fiber called a linear heat detector (LHD) on OLBC. Installing the LHD system on OLBC can effectively detect an increase in roller temperature which then becomes an early warning for operators in the control room 24 hours a day to prevent incidents that cause harm to the company due to belt fires or torn belts.
\end{abstract}

Keywords: Linear Heat Detection, Belt Conveyor, Early Warning.

\section{Pendahuluan}

\section{Latar Belakang}

\section{PENDAHULUAN}

Kondisi industri semen di Indonesia tengah menghadapi tantangan, dengan pertumbuhan ekonomi yang stagnan dan kenaikan jumlah konsumsi dalam negeri maupun luar negeri yang rendah. Tahun 2018 tercatat kelebihan pasokan sebesar 30 juta ton, kondisi ini membuat kompetisi menjadi kuat dan berimbas pada menurunnya harga semen. Kondisi ini memperberat para produsen semen.

Pada kwartal ke-2 tahun 2019 mulai terjadi peningkatan permintaan domestik yang dijawab oleh produsen semen ditengah persaingan yang kuat dengan semen impor. Beberapa hal ini diikuti usaha yang optimal dari lini produksi. Salah satu 
proses utama yang sering terganggu adalah pasokan bahan baku batu kapur dari quarry ke pabrik.

Pabrik semen yang berada di Citeureup memiliki Overland Belt Conveyor (OLBC) sejauh 7kilometer untuk mengangkut batu kapur dengan kecepatan maksimum 5.6 meter perdetik, kapasitas maksimum 4.500 ton per jam. Jika OLBC terganggu akan mengakibatkan pasokan bahan baku terhenti dan bisnis perusahaan macet.

Salah satu faktor yang mempengaruhi tercapainya kinerja sekaligus sistem manajemen perusahaan adalah faktor Keselamatan dan Kesehatan Kerja (K3). Keselamatan manusia, proses dan alat yang menjadikan kebutuhan proses produksi berjalan lancar. Permasalahan yang dapat terjadi pada pasokan batu kapur adalah breakdown pada OLBC yang diakibatkan oleh roller yang rusak, belt robek, dan bahkan berpotensi kebakaran.

Tercatat setidaknya 11 kali stop pada Bulan Juni 2019 karena kerusakan pada bearing roller, kemudian 9 kali stop pada Bulan Juli 2019, dan 10 kali stop pada Bulan Agustus 2019. Dalam rentang waktu tersebut terjadi 6 kali hampir terjadi kebakaran dan 3 kali belt robek yang diakibatkan bearing rusak, menimbulkan spark dan panas serta membakar grease. Kondisi ini menjadikan bahaya bagi para karyawan maupun pekerja kontraktor di area tersebut dan dapat menyebabkan kerugian besar bagi perusahaan. Kondisi ini dapat menimbulkan dampak buruk terhadap lingkungan karena asap terbakarnya belt yang berbahaya bagi kesehatan.

Penyebab insiden tersebut, adalah kurangnya inspeksi dan pemeliharaan pada OLBC yang disebabkan jarak inspeksi mencapai 7kilometer melintasi sungai dan 2 desa, metode inspeksi secara visual, breakdown maintenance, dan berkurangnya manpower untuk secara rutin mengawasi proses pengangkutan batu kapur tersebut. Untuk itu perlu dilakukan upaya pencegahan dengan mekanisme peringatan dini (early warning) untuk memberikan alert kepada pihak perusahaan.

Semakin berkembang ilmu pengetahuan dan teknologi, sistem kontrol otomatis membantu manusia untuk mengatasi permasalahan dengan cara yang lebih mudah. Pada industri, sitem produksi dapat dibuat kegiatan produksi yang terintegrasi menjadi efektif dan efisien.

Sistem peringatan dini atau early warning system dapat digunakan sebagai sistem kontrol otomatis untuk mendeteksi dan mencegah terjadinya insiden khususnya kebakaran pada OLBC. Early warning system dapat diterapkan pada proses yang dapat mendeteksi panas sehingga mencegah terjadinya kebakaran. Oleh karena itu, perlu dilakukan pemasangan sensor menggunakan fibre optic yang disebut linear heat detector (LHD) pada OLBC guna mendeteksi dan mencegah terjadinya insiden khususnya kebakaran dan kerusakan belt. 


\section{TINJAUAN PUSTAKA}

Vol. IX, No. 1, Januari 2020

\subsection{Batu Kapur}

Batu kapur merupakan merupakan bagian dari batuan sedimen, yang terbentuk dari proses kimia Batu kapur atau batu gamping (limestone) merupakan mineral kalsium karbonat $(\mathrm{CaCO} 3)$ yang terjadi akibat proses kimia dan organik. Secara umum mineral yang terkandung dalam batu kapur adalah kalsium karbonat kalsit sebesar 95\%, dolomit sebanyak 3\%, dan sisanya adalah mineral clay.

Dalam industri bangunan atau pertukangan batu kapur sering digunakan sebagai bahan pembuatan semen abu atau biasa dinamakan Portland. Semen sendiri sangat penting dan sering dicari karena bahan ini merupakan bahan perekat untuk industri bangunan. Tanpa semen yang berasal dari batu kapur ini maka bangunan yang terlihat sekarang ini menjadi tidak kokoh. (1)

\subsection{Conveyor}

Conveyor adalah suatu system mekanik yang mempunyai fungsi memindahkan barang dari satu tempat ke tempat yang lain. Conveyor banyak dipakai di industri untuk transportasi barang yang jumlahnya sangat banyak dan berkelanjutan. Dalam kondisi tertentu, conveyor banyak dipakai karena mempunyai nilai ekonomis dibanding transportasi berat seperti truk dan mobil pengangkut. Conveyor dapat memobilisasi barang dalam jumlah banyak dan kontinyu dari satu tempat ke tempat lain. Perpindahan tempat tersebut harus mempunyai lokasi yang tetap agar sistem conveyor mempunyai nilai ekonomis. (2)

Conveyor terdiri dari beberapa tipe yaitu roller conveyor, skate wheelconveyor, belt conveyor, dan chain conveyor. Tipe belt conveyor lebih banyak digunakan di dunia industri. Ketika belt conveyor berjalan, setengah panjangnya digunakan untuk mengangkut material, dan setengahnya lagi kembali untuk mengangkut material berikutnya. Meterial belt biasanya dibuat dari rubber atau karet, oleh karena itu belt conveyor lebih flexible dalam hal pengangkutan material yang beragam. (3) Bagian pada belt conveyor dapat dilihat pada Gambar 1.

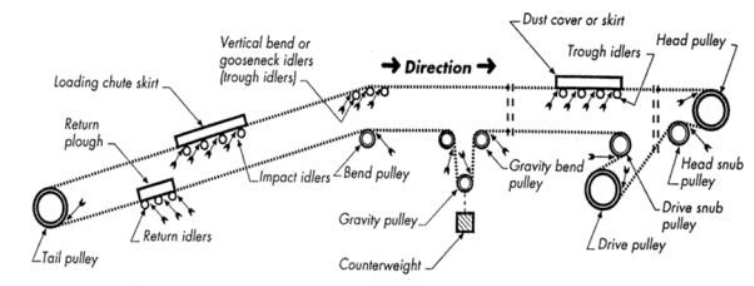

Gambar 2.1. Belt Conveyor.

\subsection{Sistem}

Sistem adalah sekumpulan elemen atau subsistem yang saling berhubungan satu dengan yang lain membentuk satu kesatuan untuk melaksanakan suatu fungsi guna mencapai suatu tujuan (4). Setiap elemen dalam sebuah sistem bekerja sesuai dengan fungsinya dan saling bekerja sama. Elemen input diubah menjadi elemen output. 
EKONOMI BISNIS DAN KEWIRAUSAHAAN

Vol. IX, No. 1, Januari 2020

Sumber daya mengalir dari elemen input melalui elemen transformasi kepada elemen output. Suatu mekanisme kontrol memantau proses transformasi agar sistem memenuhi tujuan. (4)

Suatu sistem memiliki karakteristik atau sifat tertentu, yang mencirikan suatu system (5), adalah:

1. Komponen Sistem (Components)

2. Batas Sistem (Boundary)

3. Lingkungan Luar Sistem (Environment)

4. Penghubung Sistem (Interface)

5. Masukan Sistem (Input)

6. Keluaran Sistem (Output)

7. Pengolah Sistem (Process)

8. Sasaran Sistem (Objectives)

Sistem Peringatan Dini (Early Warning System) merupakan serangkaian sistem atau alat yang berfungsi mengumpulkan informasi yang berguna untuk dijadikan sistem pengawasan. Peringatan ini merupakan tindakan memberikan informasi dengan bahasa yang mudah dicerna, dan diwujudkan dalam bentuk alarm atau sirene, yang merupakan bentuk penyampaian informasi karena merupakan cara yang paling cepat. Harapan agar orang merespon informasi dengan cepat dan tepat. Semakin dini informasi yang disampaikan, semakin longgar waktu untuk merespon.

\subsection{Linear Heat Detector}

Linear Heat Detector (LHD) merupakan detektor panas (Heat Detector) yang bekerja berdasarkan pengaruh panas (temperatur). Linear Heat Detector (LHD) dirancang untuk mendeteksi kebakaran pada tingkatan yang besar, dimana temperatur lokasi yang dilindungi mulai meningkat. LHD dan cocok untuk lingkungan yang daerahnya panas.

Sistem ini terdiri dari dua komponen yaitu kabel sensor yang berdiameter kecil dan modul interface. Kabel sensor dibuat dengan bahan yang koefisien suhu negatif, dimana perubahan suhu dapat menurunkan ketahanan sensor panas dari api menyebabkan isolasi kabel LHD dapat mencair pada suhu tertentu, yang membuat dua konduktor Trouble bersamaan sehingga menimbulkan alarm berbunyi.

Lokasi pemasangan di Conveyor untuk mendeteksi awal adanya overheat dari bearing conveyor maka LHD dapat ditempatkan di dekat roller bearing. Panas dari percikan menyebabkan isolasi kabel LHD dapat mencair pada suhu tertentu, yang memungkinkan dua konduktor trouble bersamaan sehingga menimbulkan alarm berbunyi dapat dilihat pada Gambar 2.2). 


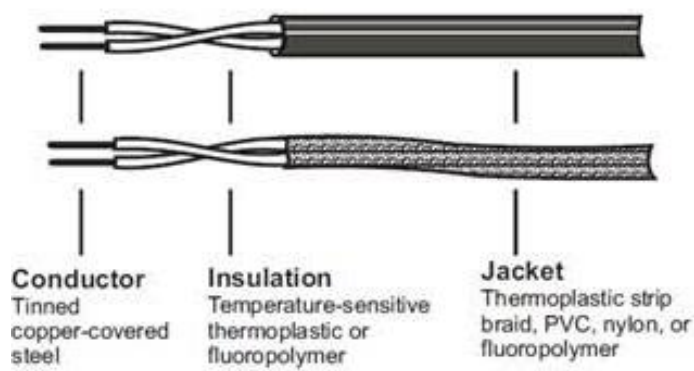

Gambar 2.2. LHD

Kelebihan atau keuntungan dari LHD ini dapat di lihat dari berbagai sisi yaitu mulai dari kefleksibelannya, tahan lama, kehandalannya dan sensitif dalam mengukur suhu. Untuk mendeteksi awal adanya overheat dari bearing conveyor maka LHD dapat ditempatkan di dekat roller bearing yang bisa dilihat pada gambar 2.3 dibawah ini.

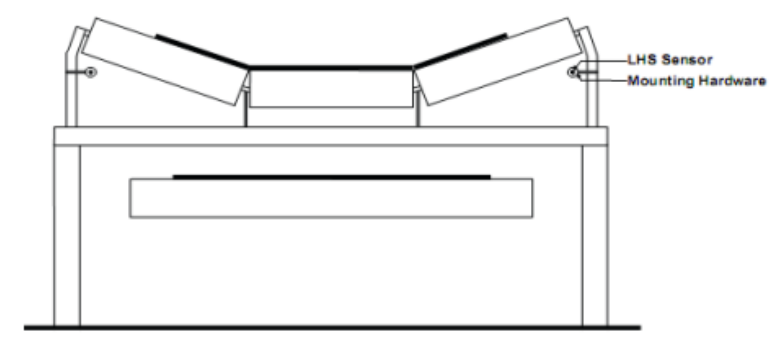

Gambar 2.3. Lokasi Penempatan LHD

\subsection{Insiden}

Kecelakaan kerja atau kecelakaan akibat kerja adalah suatu kejadian yang tidak terencana dan tidak terkendali akibat dari suatu tindakan atau reaksi suatu objek, bahan, orang, atau radiasi yang mengakibatkan cidera atau kemungkinan akibat lainnya. (7) Sementara itu pengertian kecelakaan kerja berdasarkan Frank Bird Jr. adalah kejadian yang tidak diinginkan yang terjadi dan menyebabkan kerugian pada manusia dan harta benda. Ada tiga jenis tingkat kecelakaan berdasarkan efek yang dterjadi, yaitu: (8)

a. Accident: Adalah kejadian yang tidak diinginkan yang menimbulkan kerugian baik bagi manusia maupun terhadap harta benda

b. Incident: Adalah kejadian yang tidak diinginkan yang belum menimbulkan kerugian

c. Near miss: Adalah kejadian hampir celaka dengan kata lain kejadian ini hampir menimbulkan kejadian incident ataupun accident

Sedangkan berdasarkan sumber UU No 1 Tahun 1970 tentang keselamatan kerja, kecelakaan kerja adalah suatu kejadian yang tidak diduga semula dan tidak dikehendaki, yang mengacukan proses yang telah diatur dari suatu aktifitas dan dapat menimbulkan kerugian baik korban manusia atau harta benda. 
EKONOMI BISNIS DAN KEWIRAUSAHAAN

Vol. IX, No. 1, Januari 2020

\section{METODOLOGI PENELITIAN}

Tahapan awal dalam melakukan instalasi early warning system pada OLBC adalah mempelajari rancangan sistem LHD dan melakukan survey pada OLBC untuk mengidentifikasi titik pemasangan yang tepat. Langkah selanjutnya adalah melakukan instalasi sistem LHD. Secara sederhana, konsep yang digunakan dapat dilihat pada Gambar 3.1.

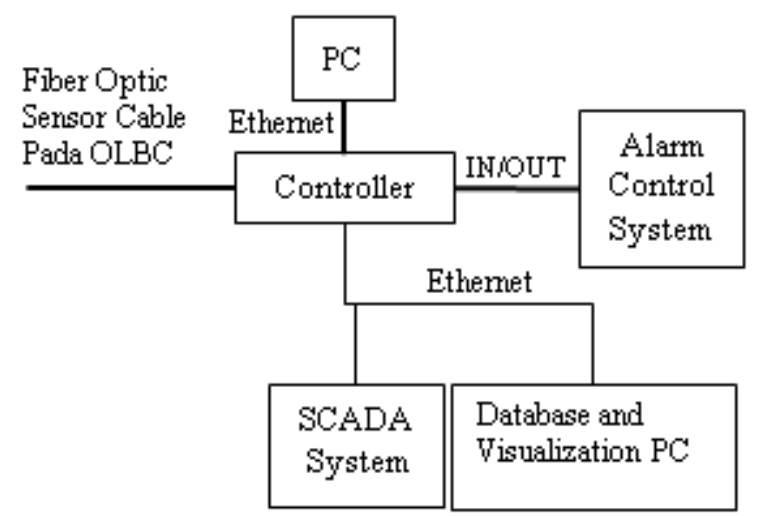

Gambar 3.1. Sistem early warning OLBC

Tahap terakhir adalah melakukan pengujian fungsi terhadap sistem LHD dapat dilihat pada Gambar 3.2.

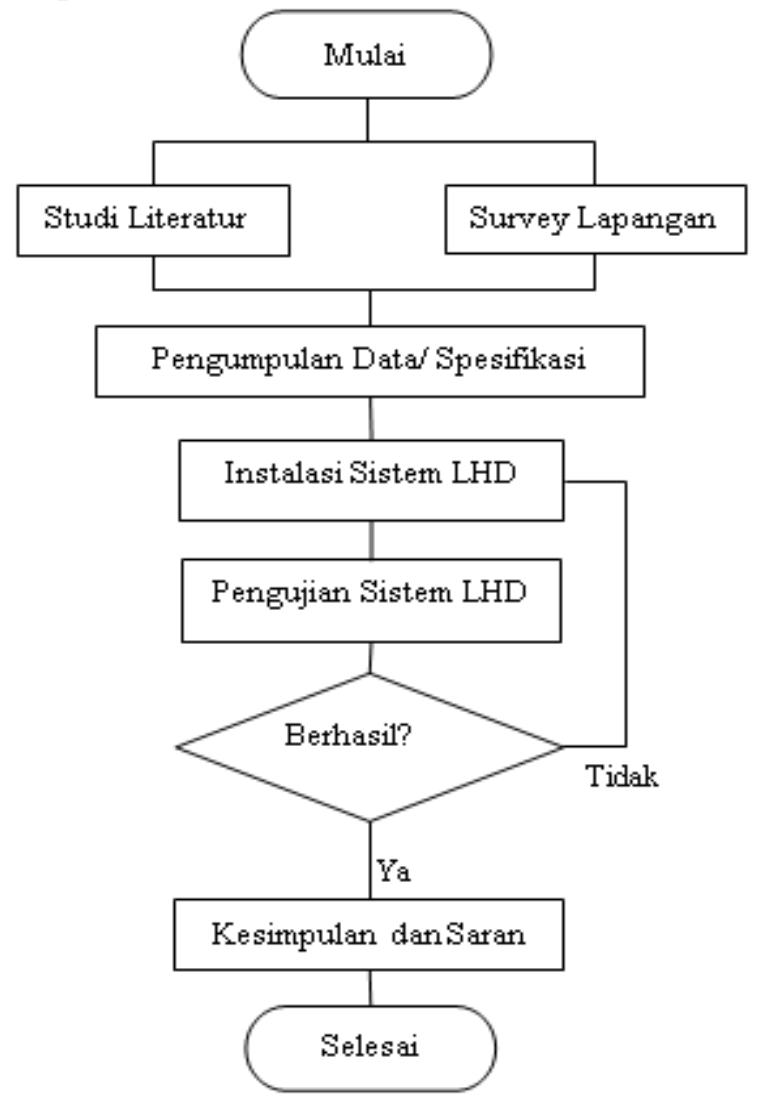

Gambar 3.2. Alur Penelitian 
EKONOMI BISNIS DAN KEWIRAUSAHAAN

Vol. IX, No. 1, Januari 2020

Spesifikasi peralatan yang digunakan adalah sebagai berikut:

a. Optical fiber sensor cable tipe E2000/APC.

b. Personal Computer untuk installation, commissioning, data storage, simulation dan visualization menggunakan Ethernet interface.

c. Alarm control system menggunakan input dan output relays dan Ethernet interface.

d. SCADA systems menggunakan Ethernet interface.

e. Ethernet atau Sensors interface.

f. DC atau AC power supply.

\section{HASIL DAN PEMBAHASAN}

Instalasi sistem LHD dilakukan pada saat kondisi OLBC stop operasi agar pekerja yang melakukan pemasangan kabel fiber optic di dekat roller aman dari benda berputar yang berpotensi terjepit dan terbawa putaran hingga cidera. Pemasangan kabel fiber optic di sisi kiri dan kanan roller untuk memonitor kedua sisi OLBC. Fiber optic sepanjang 500meter dibagi kedalam 5 zona. Hal ini untuk memudahkan identifikasi lokasi yang terjadi kenaikan temperature yang menyebabkan alarm berbunyi ditunjukkan pada Gambar 4.1.

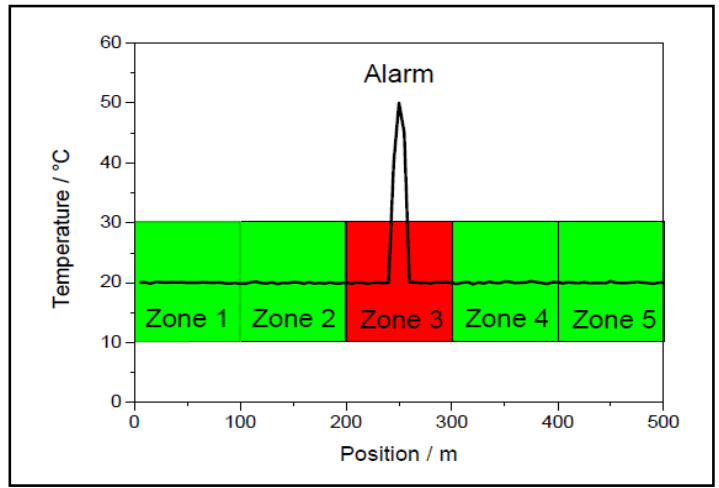

Gambar 4.1. Pembagian Zona

Instalasi selanjutnya disambung ke alarm system melalui controller yang ditunjukkan pada Gambar 4.2.

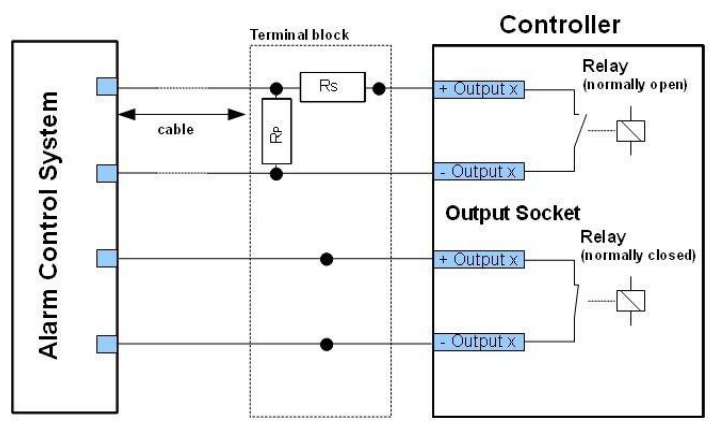

Gambar 4.2. Diagram Instalasi Alarm 
EKONOMI BISNIS DAN KEWIRAUSAHAAN

Vol. IX, No. 1, Januari 2020

Sebagai early warning dilakukan setting pada alarm dalam 2 level, yaitu prealarm dan alarm sebagai peringatan kepada operator dan pekerja di sekitar area OLBC ditunjukkan pada Tabel 4.1

Tabel.4.1. Alarm Setting dan Spacing

\begin{tabular}{|c|c|c|}
\hline Alam Settings & Max. spacing & $\begin{array}{l}\text { Max distance from } \\
\text { the wall }\end{array}$ \\
\hline 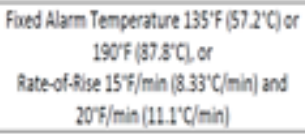 & $50 \mathrm{ft}(15.24 \mathrm{~m})$ & $25 \mathrm{ft}(7.62 \mathrm{~m})$ \\
\hline Faed Rarm Temoerature $160^{\circ}\left(711^{\prime C}\right)$ & $30 *(9.14 \mathrm{~m})$ & $15 \mathrm{ft}(4.57 \mathrm{~m})$ \\
\hline
\end{tabular}

Proses selanjutnya adalah penyambungan ke Visualization $P C$ yang telah dilengkapi software sistem LHD untuk memonitor temperature dari control room yang dapat dilihat pada Gambar 4.3

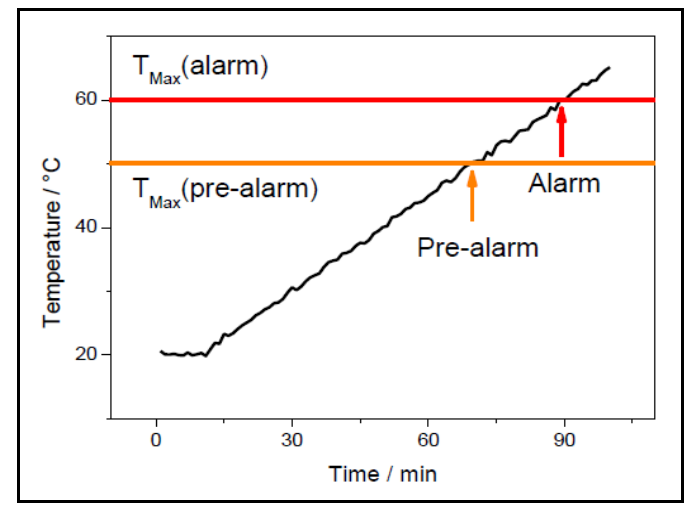

Gambar 4.3. Monitor Temperatur

Operator dapat memonitor 24 jam tingkat temperatur dan dapat dengan mudah melihat rata-rata temperature dalam kondisi normal operasi sehingga jika terdapat peningkatan signifikan pada temperatur dapat terlihat dengan jelas dan menyebabkan alarm berbunyi dapat dilihat pada Gambar 4.4.

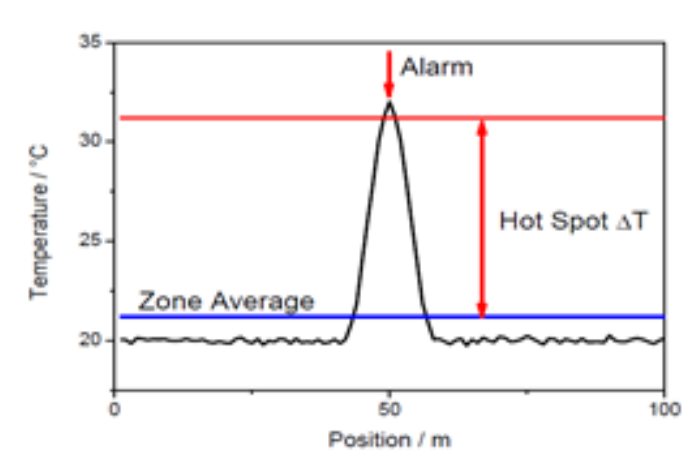

Gambar 4.4. Monitor Hot Spot 
Visualisasi pada layar komputer dapat dilihat pada Gambar 4.5.

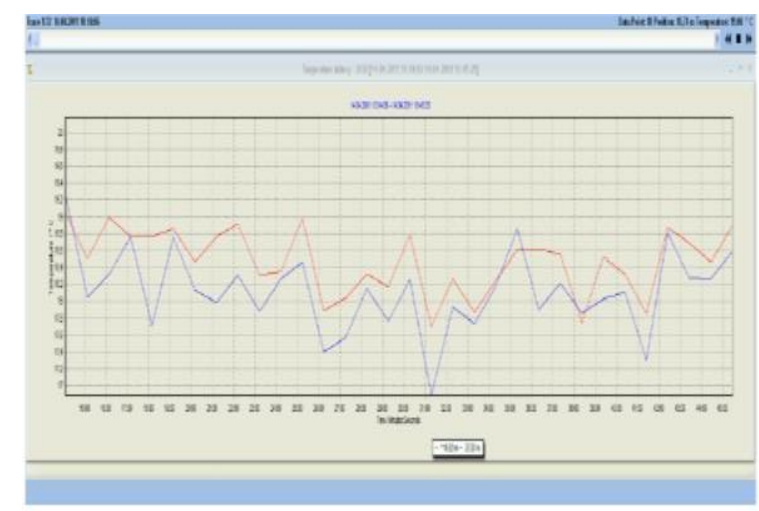

Gambar 4.5. Visualisasi pada PC

Saat alarm berbunyi tentunya diharapkan respon cepat dari operator untuk kemudian menginformasian kepada pelaksana lapangan agar menuju zona yang terdeteksi hot spot dan kemudian segera dapat diambil langkah pencegahan sehingga insiden seperti kebakaran belt dan belt robek yang disebabkan oleh kerusakan roller atau substandard roller dapat dicegah.

\section{KESIMPULAN DAN SARAN}

Kesimpulan yang dapat diambil adalah instalasi sistem LHD pada OLBC dapat secara efektif mendeteksi peningkatan temperatur roller yang kemudian menjadi early warning bagi operator di control room selama 24 jam sehari mencegah terjadinya insiden yang menimbulkan kerugian bagi perusahaan akibat kebakaran belt maupun belt robek.

Saran yang dapat diberikan adalah early warning system dengan menggunakan sistem LHD pada OLBC dapat ditingkatkan dengan menyambung jalur komunikasi dari control room ke mobile phone menggunakan rancangan aplikasi yang terintegrasi dengan platform android maupun ios, sehingga pihak yang berkepentingan dapat memonitor kondisi temperatur OLBC secara kontinyu.

\section{DAFTAR PUSTAKA}

Park et al. (2008). Effect of Magnesium Chloride and Organic Additives on The Synthesis of Aragonite Precipitated Calcium Carbonate. Journal of Crystal growth, Vol.310, p.2593-2601

Hendri, M., Jasmir., Siswanto, Agus. (2014). Miniatur Conveyor Otomatis Berbasis Mikrokontroler. Jurnal Ilmiah Media Processor, Vol.9 No.1.

Muslihudin, Muhamad Oktafianto. (2016). Analisis dan Perancangan Sistem Informasi Menggunakan Model Terstruktur dan UML. Yogyakarta: Andi. 
EKONOMI BISNIS DAN KEWIRAUSAHAAN

Vol. IX, No. 1, Januari 2020

Sulistyadi, K dan Basriman I, 2018, Sistem Produksi: Industri Manufaktur dan Jasa, Sekolah Pascasarjana Usahid, Jakarta

Sutabri, Tata. (2012). Analisis Sistem Informasi. Yogyakarta: Andi.

Yudha, Elvi Sandi. (2011). Perancangan Peletakan Sprinkler Dan Detector Pada Conveyor PT. YTL Jawa Timur Sebagai Upaya Untuk Pencegahan Dan Penanggulangan Bahaya Kebakaran. Institut Teknologi Sepuluh Nopember: Surabaya

Frank Bird Jr and George L Germain, (1990) "Practical Loss Control Leadership", Institute Publishing, USA 